\title{
Descrioulização Lexical no Contacto entre o Caboverdiano e o Português
}

\section{Dulce Pereira \\ Universidade de Lisboa}

Nas comunidades como a caboverdiana, em que um crioulo coexiste, durante um largo espaço de tempo, com uma língua de maior prestígio social, há uma tendência para que as estruturas e unidades crioulas se deixem assimilar gradualmente ou mesmo substituir pelas da língua de contacto. Este processo, a que se dá o nome de descrioulização, pode atingir todas as componentes da gramática e do léxico, dando origem a um contínuo de variedades que, em alguns casos, são dificilmente classificáveis dentro dos limites de uma ou de outra língua.

Em Cabo Verde, o facto de o português ter sido, simultaneamente, a língua-mãe, que deu o léxico no processo de formação do caboverdiano, e a língua de contacto e de prestígio durante cinco séculos, e de ainda hoje ser a única língua oficial, gerou uma teia complexa de relações entre os dois sistemas de que a descrioulização é apenas uma das componentes.

Em áreas em que os limites entre as duas línguas são nitidamente definidos, como no caso de alguns subsistemas rnorfológicos e sintácticos, os fenómenos de descrioulização são de fácil identificação. Assim, por exemplo, dado que, em contraste com o verbo português, o verbo crioulo não tem flexão de pessoa, número nem modo, a presença de um morfema flexional deste tipo associado a uma forma verbal constitui uma marca óbvia de descrioulização.

Ao nível do léxico, porém, é muito difícil classificar rigorosamente uma unidade lexical como fazendo parte integrante do sistema crioulo ou como sendo um empréstimo recente ou casual. Tal dificuldade advém de vários factores que têm em comum o facto de contribuírem para a aproximação superficial entre as duas línguas.

O léxico crioulo é na sua maioria de origem portuguesa pelo que, embora tendo sofrido, em muitos casos, transformações de ordem fonológica, sintáctica e semântica, as suas unidades mantêm frequentemente formas superficialmente idênticas às correspondentes portuguesas. Assim, nas diferentes categorias gramaticais, palavras como

kasa, mudjer, tchon, sodadi

fase, anda, tchora, sunha

bedju, burmedju, duenti

onti, ochi, gora, lonji

$d i, t i$ 
correspondem, em português, respectivamente, a

casa, mulher, chão, saudade

fazer, andar, chorar, sonhar

velho, vermelho, doente

ontem, hoje, agora, longe

de, até,

com um valor muito aproximado nos dois sistemas.

Outras unidades, porém, mantêm uma aparência fónica semelhante mas têm diferentes significados ou comportamentos sintácticos. É o caso, nomeadamente, do advérbio li e dos verbos dadji e kore. $L i$, provindo do português ali, tem o significado oposto de aqui ou cá:

CCV: e ben li

Port.: ele veio cá

Dadji deriva da forma verbal portuguesa da terceira pessoa do singular $d a$ associada ao clítico lhe (dá-lhe) reanalisada como um verbo com o significado de "bater":

CCV: e dadji na mininu

Port.: ele bateu na criança

Kore, do português correr, apenas em crioulo pode ter o valor causativo que assume na expressão

$\mathrm{CCV}$ : mininu kore arku

Port.: o menino pôs o arco a correr

Existe, por outro lado, uma estratégia discursiva muito vulgar nos grupos bilingues da comunidade crioula, sobretudo em contextos de tradição de uso do português, como na escrita, que consiste na apropriação em massa de formas lexicais portuguesas, total ou parcialmente adaptadas ao sistema fonológico crioulo, e que podem acarretar, ou não, mudanças sintácticas e semânticas.

Os textos em crioulo publicados em jornais, meios de comunicação onde naturalmente predomina a língua oficial $-\mathrm{o}$ português-, são bom exemplo deste fenómeno. O artigo do jornal Voz di Povo que se reproduz em apêndice, na variedade de Santiago, tem um interesse particular. Não só por adoptar uma grafia que, contrariando o modelo predominante desde 1979, em muito se aproxima da que veio a ser proposta pela primeira vez oficialmente, embora a título experimental, em 1998', mas também porque, vindo a público numa data especial

O decreto-lei 67/98 (Cabo Verde) define as bases do alf abeto unificado para a escrita do crioulo caboverdiano que se está já a aplicar e que vai continuar a ser aplicado, experimentalmente, durante cinco 
-as vésperas das primeiras eleições pluripartidárias em Cabo Verde- reflecte necessariamente no seu léxico as tendências de criação e apropriação de palavras novas para novas realidades.

Uma leitura rápida do título e dos primeiros parágrafos dá a qualquer falante da língua portuguesa o sentimento de reconhecimento e inteligibilidade quase imediata. Tal sentimento advém do facto de o artigo ter sido escrito por um falante bilingue que adopta a estratégia discursiva acima referida de apropriação sistemática de léxico português fonologicamente adaptado à língua crioula. $\mathrm{O}$ autor pertence a um grupo de caboverdianos com um elevado nível de instrução na língua oficial, grupo esse que é o locus por excelência do contacto linguístico e que tem um peso importante, por difusão junto dos outros grupos de falantes, na evolução do crioulo e na sua aproximação em relação ao português.

Considere-se o seguinte excerto:

Un dia antis di fin di kanpanha iletoral pa purmeru ileson lejislativu pluripartidari na nos tera di ki resultadus debe prinsipia pa un rigimi vardaderamenti dimokrátiku na nos país, nos povu sufri un choki na si rikeza kultural: more Nha Gida Mendi...

Traduzindo literalmente,

Um dia antes do fim da campanha eleitoral para as primeiras eleições legislativas pluripartidárias na nossa terra, cujos resultados devem principiar por (ser) um regime verdadeiramente democrático no nosso país, o nosso povo sofreu um choque (abalo) na sua riqueza cultural: morreu a Senhora Guida Mendes...

Cote jando o texto crioulo com a sua tradução literal, tornam-se bem evidentes, não só a correspondência total entre as formas lexicais das duas línguas, mas também a identidade das sequências sintagmáticas.

Palavras como ileson, iletoral, lejislativu, vardaderamenti, pluripartidari, rijimi, bem como miditason, prizentason, transferensa, mensaji, privinidu, statura, speransadu, midjoria (que ocorrem noutros pontos do mesmo artigo), na sua adaptação à língua crioula, tendem a reproduzir antigos padrões de apropriação e transformação da língua portuguesa no processo de formação do crioulo, tais como a reconstituição da estrutura silábica canónica CVCV (veja-se a mudança do $e$ em $i$ em miditason e rijimi, respectivamente), de que a monotongação é um caso particular (iletoral, transferensa mensaji, prizentason ) ou a passagem de $l h$ a $d j$,

anos após a data da sua publicação. Este decreto surge na sequência de outras propostas de escrita, nomeadamente a do Colóquio do Mindelo, em 1979 (cfr. Veiga 1982 ) e a que eu própria elaborei e apresentei no Forum de Alfabetização Bilingue, na cidade da Praia, em 1989 e que em muito pouco diverge da proposta of ical actual (cfr. Pereira 1989). 
em posição intervocálica, como em midjoria (do port. melhoria), à semelhança de mudjer, odju ou idja (palavras já antigas no sistema crioulo). Este constitui pois mais um factor de diluição e ocultação dos limites entre as duas línguas.

Por outro lado, a tendência conservadora de variedades com menos contacto com o português faz com que se mantenham, com poucas transformações, formas que, apesar de terem entrado na língua crioula em fases antigas, estão formalmente muito próximas do português. É o que acontece com o conector causal purkê (ou purkí, do port. porque) que ocorre sistematicamente no discurso de falantes de crioulo basilectal ou fundo, ${ }^{2}$ em contraste com o seu equivalente pamodi (do port. por (a)mor de), forma mais afastada do português actual mas mais usada pelos falantes mesolectais e acrolectais. Ambas as formas são muito antigas e podem ser atestadas em textos do século XIX. Pamodi ocorre, nomeadamente, na versão em crioulo de Santiago da Parábola do filho pródigo recolhida por Joaquim Botelho da Costa e Custódio Duarte (1886) e é referida como conjunção explicativa, a par de pabia, sima e pakí, por A. de Paula Brito, nos seus "Apontamentos para a gramática que se fala na ilha de Santiago de Cabo Verde", publicados em 1887. Também as formas porkí e pabia se encontram atestadas na "Stória d'un fidju strabagante" fornecida por António J. Ribeiro a Hugo Schuchardt.. No entanto, actualmente, purkê só muito raramente é usado pelos falantes do crioulo santiaguense menos fundo que preferem a forma pamodi.

É de Nha Nácia Gomes, analfabeta, natural de Rubera Seka, no interior de Santiago, na altura com 66 anos, o seguinte texto ${ }^{3}$ :

Bentu ki ta karega kasa torna da. Ami, kantu ki $N$ sai na rua kel dia ki fase oitu dia, $N$ piti ku tchoru ta tchora purkê e rinka fichon ku pe ku tudu.

Voltou a vir um vento daqueles que até levam as casas. Eu, quando saí à rua, no oitavo dia, pus-me a chorar porque ele arrancou o feijão com o pé, com tudo.

Se considerarmos que, por definição, a descrioulização aproxima o crioulo de Cabo Verde do português actual, poderemos ser levados a concluir que, sempre que há formas alternativas, as que estão mais próximas do português são as que indiciam descrioulização. Tal não é necessariamente verdade, como vemos neste caso, uma vez que a forma aparentemente mais próxima do português, purkêe, é, pelo contrário, um equivalente mais fundo ou basilectal de pamodi. Fenómenos como este, de cristalização e reminiscência de morfemas e lexemas morfologicamente muito próximos do português, são outro factor de opacidade na definição dos limites do léxico crioulo.

\footnotetext{
2 Os caboverdianos, intuitivamente, fazem a distinção entre um crioulo mais afastado do português, a que chamam fundu e um crioulo mais próximo do português que designam como levi.

3 Excerto de uma entrevista por mim realizada em 1985.
} 
Apesar dos múltiplos obstáculos à identificação rigorosa das fronteiras lexicais, o falante comum, intuitivamente, é capaz de distinguir se um determinado enunciado é mais português ou mais crioulo ${ }^{+}$, com base no léxico seleccionado.

$\mathrm{O}$ artigo de jornal acima referido é um bom exemplo de um discurso que podemos considerar mais português. Tal deve-se, em grande parte, à elevada percentagem de lexemas novos como kanpanha, ileson, dimokrátiku, sosio-pulitiku, etc. A introdução destes termos poderia justificar-se pela novidade do tema eleitoral e o pressuposto de que não têm correspondente em crioulo. No entanto, encontramos no mesmo texto unidades lexicais como prinsipia, presta (sirbisu) ou maior que são termos de uso mais geral e que podem facilmente ser "traduzidos" por outras unidades ou expressões lexicais, em crioulo mais fundo, respectivamente komesa, fase, e mas grandi ${ }^{5}$.

Outro aspecto determinante da identificação do texto como mais acrolectal é o facto de algumas unidades, embora fazendo parte do léxico crioulo, aí ocorrerem com um outro significado e em contextos de uso próprios da língua portuguesa. É o caso da forma verbal torna, na frase

\section{El torna un batukadera konchedu y famadu \\ Ela tornou-se uma conhecida e famosa mulher do batuque}

Onde está torna esperar-se-ia bira, já que torna, em crioulo mais fundo, tem um significado de iteração e não de mudança, como em português. Assim, diz-se

Dj'e bira bedju

Ele ficou velho

e não

* E torna bedju

mas

E torna ben

Ele voltou a vir

e não

\section{*E bira ben}

Outro processo de descrioulização muito frequente consiste na combinação inovadora de um radical e um ou mais afixos já existentes na língua, segundo o

\footnotetext{
Expressões como estas são muito vulgares no discurso metalinguístico dos falantes e reflectem a sua percepção da existência de um contínuo de variedades, por efeito do contacto com o português.

5 O próprio autor, no primeiro parágrafo do artigo. usa a expressão mas grandi, em vez de maior : ...more Nha Gida Mendi. un di kes mas grandi (sinon mas grandi propi) batukadera ki Kauberdi dja pari! (Port. morreu Nha Guida Mendes, uma das maiores (senão mesmo a maior) "batukadera" que Cabo Verde al guma vez deu à luz!).
} 


\title{
Descrioulização Lexical no Contacto entre o Caboverdiano e o Português
}

\author{
Dulce Pereira \\ Universidade de Lisboa
}

Nas comunidades como a caboverdiana, em que um crioulo coexiste, durante um largo espaço de tempo, com uma língua de maior prestígio social, há uma tendência para que as estruturas e unidades crioulas se deixem assimilar gradualmente ou mesmo substituir pelas da língua de contacto. Este processo, a que se dá o nome de descrioulização, pode atingir todas as componentes da gramática e do léxico, dando origem a um contínuo de variedades que, em alguns casos, são dificilmente classificáveis dentro dos limites de uma ou de outra língua.

Em Cabo Verde, o facto de o português ter sido, simultaneamente, a língua-mãe, que deu o léxico no processo de formação do caboverdiano, e a língua de contacto e de prestígio durante cinco séculos, e de ainda hoje ser a única língua oficial, gerou uma teia complexa de relações entre os dois sistemas de que a descrioulização é apenas uma das componentes.

Em áreas em que os limites entre as duas línguas são nitidamente definidos, como no caso de alguns subsistemas morfológicos e sintácticos, os fenómenos de descrioulização são de fácil identificação. Assim, por exemplo, dado que, em contraste com o verbo português, o verbo crioulo não tem flexão de pessoa, número nem modo, a presença de um morfema flexional deste tipo associado a uma forma verbal constitui uma marca óbvia de descrioulização.

Ao nível do léxico, porém, é muito difícil classificar rigorosamente uma unidade lexical como fazendo parte integrante do sistema crioulo ou como sendo um empréstimo recente ou casual. Tal dificuldade advém de vários factores que têm em comum o facto de contribuírem para a aproximação superficial entre as duas línguas.

O léxico crioulo é na sua maioria de origem portuguesa pelo que, embora tendo sofrido, em muitos casos, transformações de ordem fonológica, sintáctica e semântica, as suas unidades mantêm frequentemente formas superficialmente idênticas às correspondentes portuguesas. Assim, nas diferentes categorias gramaticais, palavras como

kasa, mudjer, tchon, sodadi

fase, anda, tchora, sunha

bedju, burmedju, duenti

onti, ochi, gora, lonji

$d i, t i$ 
correspondem, em português, respectivamente, a

casa, mulher, chão, saudade

fazer, andar, chorar, sonhar

velho, vermelho, doente

ontem, hoje, agora, longe

de, até,

com um valor muito aproximado nos dois sistemas.

Outras unidades, porém, mantêm uma aparência fónica semelhante mas têm diferentes significados ou comportamentos sintácticos. É o caso, nomeadamente, do advérbio li e dos verbos dadji e kore. $L i$, provindo do português ali, tem o significado oposto de aqui ou cá:

CCV: e ben li

Port.: ele veio cá

Dadji deriva da forma verbal portuguesa da terceira pessoa do singular $d a$ associada ao clítico lhe (dá-lhe) reanalisada como um verbo com o significado de "bater":

CCV: e dadji na mininu

Port.: ele bateu na criança

Kore, do português correr, apenas em crioulo pode ter o valor causativo que assume na expressão

$\mathrm{CCV}$ : mininu kore arku

Port.: o menino pôs o arco a correr

Existe, por outro lado, uma estratégia discursiva muito vulgar nos grupos bilingues da comunidade crioula, sobretudo em contextos de tradição de uso do português, como na escrita, que consiste na apropriação em massa de formas lexicais portuguesas, total ou parcialmente adaptadas ao sistema fonológico crioulo, e que podem acarretar, ou não, mudanças sintácticas e semânticas.

Os textos em crioulo publicados em jornais, meios de comunicação onde naturalmente predomina a língua oficial $-\mathrm{o}$ português-, são bom exemplo deste fenómeno. O artigo do jornal Voz di Povo que se reproduz em apêndice, na variedade de Santiago, tem um interesse particular. Não só por adoptar uma grafia que, contrariando o modelo predominante desde 1979, em muito se aproxima da que veio a ser proposta pela primeira vez oficialmente, embora a título experimental, em 1998', mas também porque, vindo a público numa data especial

O decreto-lei 67/98 (Cabo Verde) define as bases do alf abeto unificado para a escrita do crioulo caboverdiano que se está já a aplicar e que vai continuar a ser aplicado, experimentalmente, durante cinco 
-as vésperas das primeiras eleições pluripartidárias em Cabo Verde- reflecte necessariamente no seu léxico as tendências de criação e apropriação de palavras novas para novas realidades.

Uma leitura rápida do título e dos primeiros parágrafos dá a qualquer falante da língua portuguesa o sentimento de reconhecimento e inteligibilidade quase imediata. Tal sentimento advém do facto de o artigo ter sido escrito por um falante bilingue que adopta a estratégia discursiva acima referida de apropriação sistemática de léxico português fonologicamente adaptado à língua crioula. $\mathrm{O}$ autor pertence a um grupo de caboverdianos com um elevado nível de instrução na língua oficial, grupo esse que é o locus por excelência do contacto linguístico e que tem um peso importante, por difusão junto dos outros grupos de falantes, na evolução do crioulo e na sua aproximação em relação ao português.

Considere-se o seguinte excerto:

Un dia antis di fin di kanpanha iletoral pa purmeru ileson lejislativu pluripartidari na nos tera di ki resultadus debe prinsipia pa un rigimi vardaderamenti dimokrátiku na nos país, nos povu sufri un choki na si rikeza kultural: more Nha Gida Mendi...

Traduzindo literalmente,

Um dia antes do fim da campanha eleitoral para as primeiras eleições legislativas pluripartidárias na nossa terra, cujos resultados devem principiar por (ser) um regime verdadeiramente democrático no nosso país, o nosso povo sofreu um choque (abalo) na sua riqueza cultural: morreu a Senhora Guida Mendes...

Cote jando o texto crioulo com a sua tradução literal, tornam-se bem evidentes, não só a correspondência total entre as formas lexicais das duas línguas, mas também a identidade das sequências sintagmáticas.

Palavras como ileson, iletoral, lejislativu, vardaderamenti, pluripartidari, rijimi, bem como miditason, prizentason, transferensa, mensaji, privinidu, statura, speransadu, midjoria (que ocorrem noutros pontos do mesmo artigo), na sua adaptação à língua crioula, tendem a reproduzir antigos padrões de apropriação e transformação da língua portuguesa no processo de formação do crioulo, tais como a reconstituição da estrutura silábica canónica CVCV (veja-se a mudança do $e$ em $i$ em miditason e rijimi, respectivamente), de que a monotongação é um caso particular (iletoral, transferensa mensaji, prizentason ) ou a passagem de $l h$ a $d j$,

anos após a data da sua publicação. Este decreto surge na sequência de outras propostas de escrita, nomeadamente a do Colóquio do Mindelo, em 1979 (cfr. Veiga 1982 ) e a que eu própria elaborei e apresentei no Forum de Alfabetização Bilingue, na cidade da Praia, em 1989 e que em muito pouco diverge da proposta of ical actual (cfr. Pereira 1989). 
Apesar dos múltiplos obstáculos à identificação rigorosa das fronteiras lexicais, o falante comum, intuitivamente, é capaz de distinguir se um determinado enunciado é mais português ou mais crioulo ${ }^{+}$, com base no léxico seleccionado.

$\mathrm{O}$ artigo de jornal acima referido é um bom exemplo de um discurso que podemos considerar mais português. Tal deve-se, em grande parte, à elevada percentagem de lexemas novos como kanpanha, ileson, dimokrátiku, sosio-pulitiku, etc. A introdução destes termos poderia justificar-se pela novidade do tema eleitoral e o pressuposto de que não têm correspondente em crioulo. No entanto, encontramos no mesmo texto unidades lexicais como prinsipia, presta (sirbisu) ou maior que são termos de uso mais geral e que podem facilmente ser "traduzidos" por outras unidades ou expressões lexicais, em crioulo mais fundo, respectivamente komesa, fase, e mas grandi ${ }^{5}$.

Outro aspecto determinante da identificação do texto como mais acrolectal é o facto de algumas unidades, embora fazendo parte do léxico crioulo, aí ocorrerem com um outro significado e em contextos de uso próprios da língua portuguesa. É o caso da forma verbal torna, na frase

\section{El torna un batukadera konchedu y famadu \\ Ela tornou-se uma conhecida e famosa mulher do batuque}

Onde está torna esperar-se-ia bira, já que torna, em crioulo mais fundo, tem um significado de iteração e não de mudança, como em português. Assim, diz-se

Dj'e bira bedju

Ele ficou velho

e não

* E torna bedju

mas

E torna ben

Ele voltou a vir

e não

\section{*E bira ben}

Outro processo de descrioulização muito frequente consiste na combinação inovadora de um radical e um ou mais afixos já existentes na língua, segundo o

\footnotetext{
Expressões como estas são muito vulgares no discurso metalinguístico dos falantes e reflectem a sua percepção da existência de um contínuo de variedades, por efeito do contacto com o português.

5 O próprio autor, no primeiro parágrafo do artigo. usa a expressão mas grandi, em vez de maior : ...more Nha Gida Mendi. un di kes mas grandi (sinon mas grandi propi) batukadera ki Kauberdi dja pari! (Port. morreu Nha Guida Mendes, uma das maiores (senão mesmo a maior) "batukadera" que Cabo Verde al guma vez deu à luz!).
} 
modelo derivacional do português. Assim, a partir do radical crioulo konche (port. conhecer) formam-se palavras novas como diskonchedu e rakonche, à semelhança do português desconhecido e reconhecer. Apesar de dis- e ra- serem prefixos produtivos em crioulo, em particular o primeiro (veja-se disflâ, "desdizer", dismara, "desatar", diskabesia, "perder a cabeça", dismopi "desenrugar, endireitar"; rabespa "antevéspera", ramonda "voltar a mondar"), as combinações acima não são actualizadas no crioulo mais fundo. As regras e o material morfológico são crioulos. O resultado da sua aplicação é mais português.

Foram aqui focados alguns dos processos que caracterizam a descrioulização a nível lexical, independentemente dos seus possíveis efeitos na sintaxe, embora estes lhe estejam normalmente associados, como se verifica no excerto seguinte:

$Y$ nha enpenhu era ser fiel a si dizeju y a si mensajis, komu opurtunidadi di un bon sirbisu ki $N$ podeba prestaba a el y a nos kultura

À letra,

E o meu empenho era ser fiel ao seu desejo e às suas mensagens, como oportunidade de um bom serviço que eu podia prestar a ela e à nossa cultura

O simples facto de o autor ter seleccionado as palavras portuguesas fiel e prestar obrigou, por inércia, à actualização de sintagmas preposicionais introduzidos pela preposição $a$ (segundo o modelo português) que não faz parte do léxico gramatical crioulo: fiel a si dizeju y a si mensajis; $N$ podeba prestaba a el y a nos kultura.

Em suma, o léxico é uma das áreas mais vulneráveis à descrioulização na comunidade linguística caboverdiana, devido:

a. às características do próprio léxico referencial (enquanto componente aberta), e do saber lexical, sujeito a mudanças e dependente da capacidade individual de memorização;

b. ao facto de os falantes, em geral, não terem consciência dos limites entre os léxicos das duas línguas, inconsciência essa reforçada pelo facto de o crioulo não ter sido ainda normalizado e de os falantes considerarem, como é típico das comunidades de tradição oral, que "em crioulo tudo é possível";

c. à inexistência, nos grupos bilingues, de condições ou meios de aquisição, memorização e activação do léxico mais fundo, uma vez que não há instrução em crioulo;

d. ao sentimento, muitas vezes fundado, de que há áreas temáticas para as quais faltam designações em crioulo;

e. ao facto de não ser necessário dominar a estrutura sintáctica da língua portuguesa para o falante dar uma imagem exterior de estar a falar mais português, bastando, para isso, usar um certo número de unidades lexicais desta língua; 
f. à possibilidade que a adaptação do léxico português à fonologia crioula dá ao falante de se identificar ambiguamente com as duas línguas em simultâneo.

Apesar das vantagens sociais que possam advir da descrioulização a nível lexical, numa altura em que a comunidade caboverdiana tem como objectivo, a curto prazo, oficializar a língua crioula, é não só interessante para a investigação, mas também fundamental do ponto de vista pragmático e da planificação linguística, definir critérios que permitam identificar as unidades que fazem parte integrante do léxico crioulo e aquelas que são apropriações recentes ou ad hoc. A oficialização implica a normalização e instrumentalização da língua o que, a nível do léxico, se traduz pela selecção das unidades lexicais (e definição da sua forma) a incluir no léxico de referência e a usar em contextos oficiais, como o ensino e os meios de comunicação.

Dado que o contacto específico entre um crioulo e uma língua oficial lexicalmente afim não se faz pela mera coexistência entre as duas línguas, nitidamente delimitadas, mas antes cria um contínuo de variedades entre elas, os critérios de identificação dos dois tipos de unidades lexicais acima referidos deverão ter em conta essa realidade e ser formulados de modo a obter resultados, não em termos discretos (sim vs. não, crioulo vs. português), mas também eles em termos de continuidade (mais ou menos, mais crioulo ou mais português). Em particular na zona acrolectal do contínuo gerado pela descrioulização é muitas vezes impossível afirmar se uma unidade é crioula ou portuguesa porque ela pode ser crioula $e$ portuguesa. A questão que se coloca é, então, a de saber quais os critérios para classificar uma unidade como menos crioula.

Consideremos alguns critérios possíveis.

\section{A unidade lexical}

a. Não foi atestada anteriormente na língua crioula.

Este critério é de muito difícil aplicação na fase actual de estudo do caboverdiano, dado que as poucas descrições lexicais existentes ${ }^{6}$ abrangem apenas um subconjunto muito limitado do acervo lexical crioulo, além de que assentam elas próprias em critérios variáveis e nem sempre explícitos.

Por outro lado, os documentos em crioulo a que temos acesso já desde o século XIX são escritos, o que pressupõe o domínio do português por parte dos seus autores (para além de alguns deles serem portugueses, a instrução em Cabo Verde foi sempre em português), e implica a interferência desta língua.

b. Viola as regras fonológicas da língua crioula.

6 Cfr. Pires / Hutchison (1983), Fernandes (1990) e Quint-Abrial (1998). 
Esta é uma situação que raramente se verifica já que uma das características da descrioulização, a nível lexical, do caboverdiano consiste precisamente na adaptação fonológica da palavra importada.

c. Viola as regras morfológicas da língua crioula.

A língua caboverdiana é menos resistente, mais permeável à introdução da morfologia derivacional do que à da morfologia flexional. No artigo de jornal em análise, nomeadamente, de todas as formas verbais realizadas, apenas surgem, como formas flexionadas, fugindo à regra do sistema verbal crioulo, foi (do port. foi, forma do verbo ser: 3 ocorrências), e teve (do port. tive, forma do verbo ter).

Sendo os afixos derivacionais uma classe fechada e o número dos prefixos crioulos muito reduzido, torna-se mais fácil identificar os afixos recentemente importados do português (autonomamente, ou associados à palavra como um todo).

O uso do sufixo -menti (do port. -mente), que vamos encontrar em palavras como vardaderamenti ou firmimenti e que, seguindo o modelo português, se associa a um adjectivo para formar um advérbio, vem contrariar uma regra muito geral em crioulo que consiste na justaposição simples do adjectivo à direita do verbo com a mesma função adverbial, como em e papia richu (Port. ele falou muito alto), $e$ ta anda richu (Port. ele anda a grande velocidade), e papia dretu (Port. ele falou bem) ou e papia maguadu (Port. ele falou com mágoa).

Poderemos então afirmar que o uso de afixos como -menti contribui para a classificação de uma unidade lexical como menos crioula.

d. Associa à forma crioula o significado da forma portuguesa correspondente.

É o caso da forma verbal torna acima referida (na expressão e torna un batukadera konchedu y famadu), quando assume o valor semântico de mudança (como em português) e não o de iteração (como em crioulo).

Este é um dos critérios de mais complexa aplicação, já que a manutenção da forma torna frequentemente difícil detectar a existência de assimilação semântica. A palavra diskonche, por exemplo, que tem o significado de "deixar de conhecer, esquecer", só poderá ser considerada como uma unidade menos crioula se usada com o significado de "não conhecer, desconhecer", como em português. Mesmo no caso de a forma ter o significado de "esquecer" é difícil decidir se se trata de uma mudança semântica de uma forma importada directamente do português ou antes de uma forma criada pela aplicação das regras morfológicas do sistema crioulo por prefixação (dis- + konche), com uma semântica crioula, ou ainda se ambas as hipóteses são válidas i. é, se houve criação e importação de duas unidades homófonas. 
O facto de as duas línguas terem léxicos superficialmente muito semelhantes favorece, como vimos, a homofonia. Dado o contacto linguístico, os falantes podem em qualquer altura importar palavras portuguesas que, pelo processo de adaptação fonológica à língua crioula, ganham uma forma expressiva idêntica à de outras há muito integradas no sistema. Como aconteceria, por exemplo, se num dado momento alguns falantes passassem a associar, por influência do português, o conceito de 'cão pequeno/não adulto' a katchor (forma crioula fonologicamente adaptada do português cachorro), e não a 'cão', como actualmente acontece em caboverdiano.

Só a aplicação convergente dos vários critérios aduzidos permitirá a identificação das unidades que indiciam descrioulização.

Por outro lado, na descrição sistemática do crioulo e na produção de materiais de referência não se poderão ignorar os factores de ordem não linguística correlacionáveis com os dados que lhes servem de base. Tendo em consideração que a descrioulização, em Cabo Verde, assume a forma de assimilação ao português, é fácil identificar, como factores favoráveis à ocorrência de unidades recentemente importadas ou descrioulizadas,

a. um grau elevado de instrução em português,

b. a selecção de tópicos referentes a realidades novas,

c. as situações definidas como de uso da língua oficial,

d. a escrita.

Serão, assim, contextos a evitar ou a considerar cautelosamente na recolha de dados para a descrição da língua crioula mais funda, qualquer que seja a metodologia adoptada.

A descrioulização, numa perspectiva estritamente linguística, não é mais que uma forma particular de evolução de uma língua por efeito do contacto com outras. Do ponto de vista das comunidades crioulas, porém, a descrioulização tem consequências mais dramáticas já que, se a assimilação for consumada, levará ao desaparecimento da língua.

Distinguir o léxico mais fundo do mais leve pode assim ter um interesse pragmático imediato, em particular quando, como em Cabo Verde, se tende para a oficialização do crioulo.

Feita a distinção, a decisão sobre o interesse linguístico das unidades lexicais mais próximas do português e a sua inclusão no léxico de referência oficial dependerá, entre outros aspectos, da sua funcionalidade, uma vez que, como a palavra ileson acima mencionada, poderão ter o papel de preencher lacunas do sistema em áreas temáticas novas. Também as características próprias do discurso escrito, na sua 
modelo derivacional do português. Assim, a partir do radical crioulo konche (port. conhecer) formam-se palavras novas como diskonchedu e rakonche, à semelhança do português desconhecido e reconhecer. Apesar de dis- e ra- serem prefixos produtivos em crioulo, em particular o primeiro (veja-se disflâ, "desdizer", dismara, "desatar", diskabesia, "perder a cabeça", dismopi "desenrugar, endireitar"; rabespa "antevéspera", ramonda "voltar a mondar"), as combinações acima não são actualizadas no crioulo mais fundo. As regras e o material morfológico são crioulos. O resultado da sua aplicação é mais português.

Foram aqui focados alguns dos processos que caracterizam a descrioulização a nível lexical, independentemente dos seus possíveis efeitos na sintaxe, embora estes lhe estejam normalmente associados, como se verifica no excerto seguinte:

$Y$ nha enpenhu era ser fiel a si dizeju y a si mensajis, komu opurtunidadi di un bon sirbisu ki $N$ podeba prestaba a el y a nos kultura

À letra,

E o meu empenho era ser fiel ao seu desejo e às suas mensagens, como oportunidade de um bom serviço que eu podia prestar a ela e à nossa cultura

O simples facto de o autor ter seleccionado as palavras portuguesas fiel e prestar obrigou, por inércia, à actualização de sintagmas preposicionais introduzidos pela preposição $a$ (segundo o modelo português) que não faz parte do léxico gramatical crioulo: fiel a si dizeju y a si mensajis; $N$ podeba prestaba a el y a nos kultura.

Em suma, o léxico é uma das áreas mais vulneráveis à descrioulização na comunidade linguística caboverdiana, devido:

a. às características do próprio léxico referencial (enquanto componente aberta), e do saber lexical, sujeito a mudanças e dependente da capacidade individual de memorização;

b. ao facto de os falantes, em geral, não terem consciência dos limites entre os léxicos das duas línguas, inconsciência essa reforçada pelo facto de o crioulo não ter sido ainda normalizado e de os falantes considerarem, como é típico das comunidades de tradição oral, que "em crioulo tudo é possível";

c. à inexistência, nos grupos bilingues, de condições ou meios de aquisição, memorização e activação do léxico mais fundo, uma vez que não há instrução em crioulo;

d. ao sentimento, muitas vezes fundado, de que há áreas temáticas para as quais faltam designações em crioulo;

e. ao facto de não ser necessário dominar a estrutura sintáctica da língua portuguesa para o falante dar uma imagem exterior de estar a falar mais português, bastando, para isso, usar um certo número de unidades lexicais desta língua; 
f. à possibilidade que a adaptação do léxico português à fonologia crioula dá ao falante de se identificar ambiguamente com as duas línguas em simultâneo.

Apesar das vantagens sociais que possam advir da descrioulização a nível lexical, numa altura em que a comunidade caboverdiana tem como objectivo, a curto prazo, oficializar a língua crioula, é não só interessante para a investigação, mas também fundamental do ponto de vista pragmático e da planificação linguística, definir critérios que permitam identificar as unidades que fazem parte integrante do léxico crioulo e aquelas que são apropriações recentes ou ad hoc. A oficialização implica a normalização e instrumentalização da língua o que, a nível do léxico, se traduz pela selecção das unidades lexicais (e definição da sua forma) a incluir no léxico de referência e a usar em contextos oficiais, como o ensino e os meios de comunicação.

Dado que o contacto específico entre um crioulo e uma língua oficial lexicalmente afim não se faz pela mera coexistência entre as duas línguas, nitidamente delimitadas, mas antes cria um contínuo de variedades entre elas, os critérios de identificação dos dois tipos de unidades lexicais acima referidos deverão ter em conta essa realidade e ser formulados de modo a obter resultados, não em termos discretos (sim vs. não, crioulo vs. português), mas também eles em termos de continuidade (mais ou menos, mais crioulo ou mais português). Em particular na zona acrolectal do contínuo gerado pela descrioulização é muitas vezes impossível afirmar se uma unidade é crioula ou portuguesa porque ela pode ser crioula $e$ portuguesa. A questão que se coloca é, então, a de saber quais os critérios para classificar uma unidade como menos crioula.

Consideremos alguns critérios possíveis.

\section{A unidade lexical}

a. Não foi atestada anteriormente na língua crioula.

Este critério é de muito difícil aplicação na fase actual de estudo do caboverdiano, dado que as poucas descrições lexicais existentes ${ }^{6}$ abrangem apenas um subconjunto muito limitado do acervo lexical crioulo, além de que assentam elas próprias em critérios variáveis e nem sempre explícitos.

Por outro lado, os documentos em crioulo a que temos acesso já desde o século XIX são escritos, o que pressupõe o domínio do português por parte dos seus autores (para além de alguns deles serem portugueses, a instrução em Cabo Verde foi sempre em português), e implica a interferência desta língua.

b. Viola as regras fonológicas da língua crioula.

6 Cfr. Pires / Hutchison (1983), Fernandes (1990) e Quint-Abrial (1998). 
Esta é uma situação que raramente se verifica já que uma das características da descrioulização, a nível lexical, do caboverdiano consiste precisamente na adaptação fonológica da palavra importada.

c. Viola as regras morfológicas da língua crioula.

A língua caboverdiana é menos resistente, mais permeável à introdução da morfologia derivacional do que à da morfologia flexional. No artigo de jornal em análise, nomeadamente, de todas as formas verbais realizadas, apenas surgem, como formas flexionadas, fugindo à regra do sistema verbal crioulo, foi (do port. foi, forma do verbo ser: 3 ocorrências), e teve (do port. tive, forma do verbo ter).

Sendo os afixos derivacionais uma classe fechada e o número dos prefixos crioulos muito reduzido, torna-se mais fácil identificar os afixos recentemente importados do português (autonomamente, ou associados à palavra como um todo).

O uso do sufixo -menti (do port. -mente), que vamos encontrar em palavras como vardaderamenti ou firmimenti e que, seguindo o modelo português, se associa a um adjectivo para formar um advérbio, vem contrariar uma regra muito geral em crioulo que consiste na justaposição simples do adjectivo à direita do verbo com a mesma função adverbial, como em e papia richu (Port. ele falou muito alto), $e$ ta anda richu (Port. ele anda a grande velocidade), e papia dretu (Port. ele falou bem) ou e papia maguadu (Port. ele falou com mágoa).

Poderemos então afirmar que o uso de afixos como -menti contribui para a classificação de uma unidade lexical como menos crioula.

d. Associa à forma crioula o significado da forma portuguesa correspondente.

É o caso da forma verbal torna acima referida (na expressão e torna un batukadera konchedu y famadu), quando assume o valor semântico de mudança (como em português) e não o de iteração (como em crioulo).

Este é um dos critérios de mais complexa aplicação, já que a manutenção da forma torna frequentemente difícil detectar a existência de assimilação semântica. A palavra diskonche, por exemplo, que tem o significado de "deixar de conhecer, esquecer", só poderá ser considerada como uma unidade menos crioula se usada com o significado de "não conhecer, desconhecer", como em português. Mesmo no caso de a forma ter o significado de "esquecer" é difícil decidir se se trata de uma mudança semântica de uma forma importada directamente do português ou antes de uma forma criada pela aplicação das regras morfológicas do sistema crioulo por prefixação (dis- + konche), com uma semântica crioula, ou ainda se ambas as hipóteses são válidas i. é, se houve criação e importação de duas unidades homófonas. 
O facto de as duas línguas terem léxicos superficialmente muito semelhantes favorece, como vimos, a homofonia. Dado o contacto linguístico, os falantes podem em qualquer altura importar palavras portuguesas que, pelo processo de adaptação fonológica à língua crioula, ganham uma forma expressiva idêntica à de outras há muito integradas no sistema. Como aconteceria, por exemplo, se num dado momento alguns falantes passassem a associar, por influência do português, o conceito de 'cão pequeno/não adulto' a katchor (forma crioula fonologicamente adaptada do português cachorro), e não a 'cão', como actualmente acontece em caboverdiano.

Só a aplicação convergente dos vários critérios aduzidos permitirá a identificação das unidades que indiciam descrioulização.

Por outro lado, na descrição sistemática do crioulo e na produção de materiais de referência não se poderão ignorar os factores de ordem não linguística correlacionáveis com os dados que lhes servem de base. Tendo em consideração que a descrioulização, em Cabo Verde, assume a forma de assimilação ao português, é fácil identificar, como factores favoráveis à ocorrência de unidades recentemente importadas ou descrioulizadas,

a. um grau elevado de instrução em português,

b. a selecção de tópicos referentes a realidades novas,

c. as situações definidas como de uso da língua oficial,

d. a escrita.

Serão, assim, contextos a evitar ou a considerar cautelosamente na recolha de dados para a descrição da língua crioula mais funda, qualquer que seja a metodologia adoptada.

A descrioulização, numa perspectiva estritamente linguística, não é mais que uma forma particular de evolução de uma língua por efeito do contacto com outras. Do ponto de vista das comunidades crioulas, porém, a descrioulização tem consequências mais dramáticas já que, se a assimilação for consumada, levará ao desaparecimento da língua.

Distinguir o léxico mais fundo do mais leve pode assim ter um interesse pragmático imediato, em particular quando, como em Cabo Verde, se tende para a oficialização do crioulo.

Feita a distinção, a decisão sobre o interesse linguístico das unidades lexicais mais próximas do português e a sua inclusão no léxico de referência oficial dependerá, entre outros aspectos, da sua funcionalidade, uma vez que, como a palavra ileson acima mencionada, poderão ter o papel de preencher lacunas do sistema em áreas temáticas novas. Também as características próprias do discurso escrito, na sua 
tensão entre a necessidade de economia e velocidade de processamento e ao mesmo tempo de explicitação de elementos e relações que, na oralidade, são proporcionados pelo contexto situacional, obrigam a uma codificação gramatical que pode levar, com vantagem, à adopção e adaptação de um léxico gramatical português (veja-se o caso dos conectores interfrásicos e textuais, como pur isu).

Uma outra questão se coloca: até que ponto é que (tal como aconteceu no século XVI com a entrada maciça de palavras do latim literário, adaptadas morfologicamente ao português), a presença de unidades lexicais mais leves não vem permitir uma maior diversidade estilística e, portanto, enriquecer o crioulo? $\mathrm{Na}$ verdade, a riqueza implica acumulação e não substituição, o que, perante a omnipresença e pressão da língua portuguesa (cuja força -e vitalidade-não se pode comparar à longínqua influência de uma língua morta) só pode ser garantido pela própria normalização e oficialização do crioulo, a par do português.

Cabe aqui citar um provérbio crioulo que diz: ken ki tene pachencha ta pari fidju branku, "quem tem paciência dá à luz filhos brancos", esperando que a paciência da investigação sobre o crioulo venha contrariar, neste caso, a sabedoria popular. Porque o filho branco da descrioulização traz em si a morte da mãe negra e duas línguas, como duas cores, são sempre maior riqueza que uma só.

\section{Referências Bibliográficas}

Brito, A. De Paula (1887): "Dialectos Crioulos-Portugueses. Apontamentos para a Gramática que se fala na ilha de Santiago de Cabo Verde, Revista pelo Exm ${ }^{\circ} \mathrm{Sr}$. F. Adolfo Coelho, Boletim da Sociedade de Geografia de Lisboa, $7^{\text {a }}$ Série, 10: 611-669.

Costa, J. B. / Duarte, J. (1886): "O Creoulo de Cabo Verde. Breves Estudos sobre o Creoulo das Ilhas de Cabo Verde oferecidos ao Dr. Hugo Schuchardt", Boletim da Sociedade de Geografia deLisboa, 6a Série, 6: 325-388.

Fernandes, N. (1990): Léxico do Dialecto Crioulo do Arquipélago de Cabo Verde (Mindelo: Ed. de autor).

Hazaël-Massieux, M.-C.(1993): Écrire en Créole. Oralité et Écriture aux Antilles (Paris: L'Harmattan).

Pereira, D. (1989): “Crioulo de Cabo Verde: Proposta de Grafia”, Revista Internacional de Língua Portuguesa, 2: 41-48.

Pires, J. / Hutchison, J. (1983): Disionariu Preliminariu Kriolu (Boston: Funkul ño Lobu).

Quint-Abrial, N. (1998): Dicionário Caboverdiano-Português. Variante de Santiago (Lisboa: Verbalis).

Schuchardt, H. (1888): "Beiträge zur Kenntnis des Kreolischen Romanisch." I. Allgemeineres über das Negerportugiesische. Zeitschrift für Romanische Philologie, 12: 242-254.

Veiga, M. (1982): Diskrison Strutural di Lingua Kabuverdianu (Praia: Instituto Caboverdiano do Livro). 


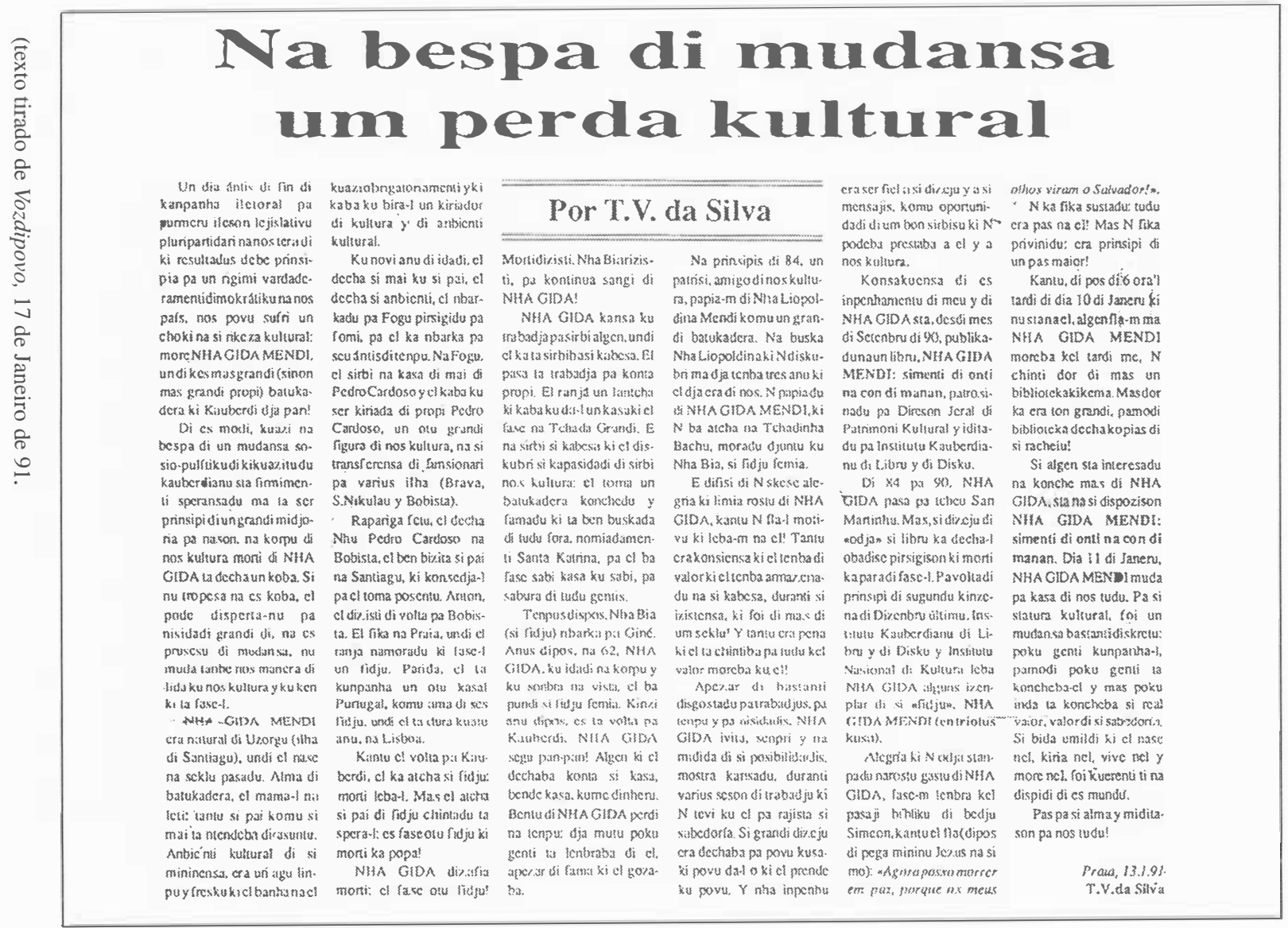

